4

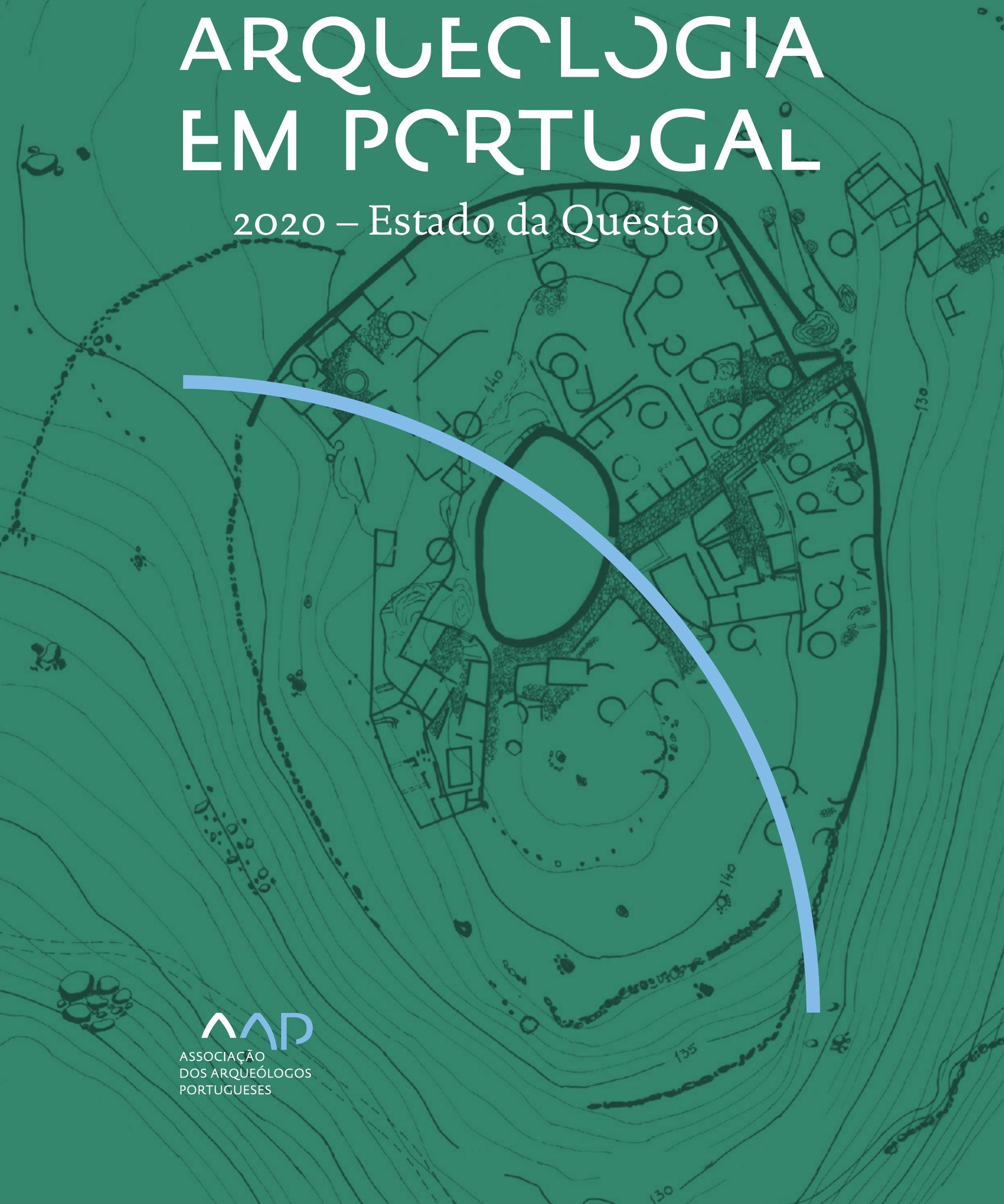


Coordenação editorial: José Morais Arnaud, César Neves e Andrea Martins Design gráfico: Flatland Design

AAP - ISBN: 978-972-9451-89-8

CITCEM - ISBN: 978-989-8970-25-1

Associação dos Arqueólogos Portugueses e CITCEM

Lisboa, 2020

O conteúdo dos artigos é da inteira responsabilidade dos autores. Sendo assim a Associação dos Arqueólogos Portugueses declina qualquer responsabilidade por eventuais equívocos ou questões de ordem ética e legal.

Desenho de capa:

Planta do castro de Monte Mozinho (Museu Municipal de Penafiel).

\section{$\hat{\wedge} \mathrm{P}$}

DOS ARQUEÓLOGOS PORTUGUESES

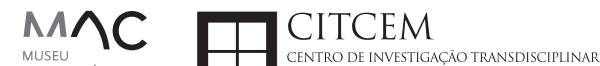
MUSEU
ARQUELLÓGICO
DO CARMO
U.PORTO

FLUP FACULDADE DE LETRAS
UNIVERSIDADE DO PORTO

Apoio

EC para a Ciência 


\section{Índice}

15 Prefácio

José Morais Arnaud

\section{Historiografia e Teoria}

17 Território, comunidade, memória e emoção: a contribuição da história da arqueologia (algumas primeiras e breves reflexões)

Ana Cristina Martins

25 Como descolonizar a arqueologia portuguesa?

Rui Gomes Coelho

41 Arqueologia e Modernidade: uma revisitação pessoal e breve de alguns aspetos da obra homónima de Julian Thomas de 2004

Vítor Oliveira Jorge

57 Dados para a História das Mulheres na Arqueologia portuguesa, dos finais do século XIX aos inícios do século XX: números, nomes e tabelas

Filipa Dimas / Mariana Diniz

73 Retractos da arqueologia portuguesa na imprensa: (in)visibilidades no feminino

Catarina Costeira / Elsa Luís

85 Arqueologia e Arqueólogos no Norte de Portugal Jacinta Bugalhão

101 Vieira Guimarães (1864-1939) e a arqueologia em Tomar: uma abordagem sobre o território e as gentes

João Amendoeira Peixoto / Ana Cristina Martins

115 Os memoráveis? A arqueologia algarvia na imprensa nacional e regional na presente centúria (2001-2019): características, visões do(s) passado(s) e a arqueologia

enquanto marca

Frederico Agosto / João Silva

129 A Evolução da Arqueologia Urbana e a Valorização Patrimonial no Barlavento Algarvio: Os casos de Portimão e Silves

Artur Mateus / Diogo Varandas / Rafael Boavida

\section{Gestão, Valorização e Salvaguarda do Património}

145 O Caderno Reivindicativo e as condições de trabalho em Arqueologia Miguel Rocha / Liliana Matias Carvalho / Regis Barbosa / Mauro Correia / Sara Simões / Jacinta Bugalhão / Sara Brito / Liliana Veríssimo Carvalho / Richard Peace / Pedro Peça / Cézer Santos

155 Os Estudos de Impacte Patrimonial como elemento para uma estratégia sustentável de minimização de impactes no âmbito de reconversões agrícolas Tiago do Pereiro

165 Salvaguarda de Património arqueológico em operações florestais: gestão e sensibilização Filipa Bragança / Gertrudes Zambujo / Sandra Lourenço / Belém Paiva / Carlos Banha / Frederico Tatá Regala / Helena Moura / Jacinta Bugalhão / João Marques / José Correia / Pedro Faria / Samuel Melro

179 Os valores do Património: uma investigação sobre os Sítios Pré-históricos de Arte Rupestre do Vale do Rio Côa e de Siega Verde José Paulo Francisco 
189 Conjugando recursos arqueológicos e naturais para potenciar as visitas ao Geoparque Litoral de Viana do Castelo (Noroeste de Portugal)

Hugo A. Sampaio / Ana M.S. Bettencourt / Susana Marinho / Ricardo Carvalhido

203 Áreas de Potencial Arqueológico na Região do Médio Tejo: Modelo Espacial Preditivo Rita Ferreira Anastácio / Ana Filipa Martins / Luiz Oosterbeek

223 Património Arqueológico e Gestão Territorial: O contributo da Arqueologia para a revisão do PDM de Avis

Ana Cristina Ribeiro

237 A coleção arqueológica do extinto Museu Municipal do Porto - Origens, Percursos e Estudos

Sónia Couto

251 Valpaços - uma nova carta arqueológica

Pedro Pereira / Maria de Fátima Casares Machado

263 Arqueologia na Cidade de Peniche

Adriano Constantino / Luís Rendeiro

273 Arqueologia Urbana: a cidade de Lagos como caso de Estudo Cátia Neto

285 Estratégias de promoção do património cultural subaquático nos Açores. O caso da ilha do Faial

José Luís Neto / José Bettencourt / Luís Borges / Pedro Parreira

297 Carta Arqueológica da Cidade Velha: Uma primeira abordagem

Jaylson Monteiro / Nireide Tavares / Sara da Veiga / Claudino Ramos / Edson Brito /

Carlos Carvalho / Francisco Moreira / Adalberto Tavares

311 Antropologia Virtual: novas metodologias para a análise morfológica e funcional Ricardo Miguel Godinho / Célia Gonçalves

\section{Didáctica da Arqueologia}

327 Como os projetos de Arqueologia podem contribuir para uma comunidade culturalmente mais consciente Alexandra Figueiredo / Claúdio Monteiro / Adolfo Silveira / Ricardo Lopes

337 Educação Patrimonial - Um cidadão esclarecido é um cidadão ativo! Ana Paula Almeida

351 A aproximação da Arqueologia à sala de aula: um caso de estudo no $3^{\circ}$ ciclo do Ensino Básico Luís Serrão Gil

363 Arqueologia 3.o - Pensar e comunicar a Arqueologia para um futuro sustentável Mónica Rolo

377 “Conversa de Arqueólogos" - Divulgar a Arqueologia em tempos de Pandemia Diogo Teixeira Dias

389 Escola Profissional de Arqueologia: desafios e oportunidades Susana Nunes / Dulcineia Pinto / Júlia Silva / Ana Mascarenhas

399 Os Museus de Arqueologia e os Jovens: a oferta educativa para o público adolescente Beatriz Correia Barata / Leonor Medeiros

411 O museu universitário como mediador entre a ciência e a sociedade: o exemplo da secção de arqueologia no Museu de História Natural e da Ciência da Universidade do Porto (MHNC-UP)

Rita Gaspar 
421 Museu de Lanifícios: Real Fábrica de Panos. Atividades no âmbito da Arqueologia Beatriz Correia Barata / Rita Salvado

427 Arqueologia Pública e o caso da localidade da Mata (Torres Novas) Cláudia Manso / Ana Rita Ferreira / Cristiana Ferreira / Vanessa Cardoso Antunes

431 Do sítio arqueológico ao museu: um percurso (também) didático Lídia Fernandes

447 Estão todos convidados para a Festa! E para dançar também... O projecto do Serviço Educativo do Museu Arqueológico do Carmo na $5^{\underline{a}}$ Edição da Festa da Arqueologia Rita Pires dos Santos

459 O “Clã de Carenque”, um projeto didático de arqueologia Eduardo Gonzalez Rocha

469 Mediação cultural: peixe que puxa carroça nas Ruínas Romanas de Troia Inês Vaz Pinto / Ana Patrícia Magalhães / Patrícia Brum / Filipa Santos

481 Didática Arqueológica, experiências do Projeto Mértola Vila Museu Maria de Fátima Palma / Clara Rodrigues / Susana Gómez / Lígia Rafael

\section{Arte Rupestre}

497 Os inventários de arte rupestre em Portugal Mila Simões de Abreu

513 O projeto FIRST-ART - conservação, documentação e gestão das primeiras manifestações de arte rupestre no Sudoeste da Península Ibérica: as grutas do Escoural e Maltravieso Sara Garcês / Hipólito Collado / José Julio García Arranz / Luiz Oosterbeek / António Carlos Silva / Pierluigi Rosina / Hugo Gomes / Anabela Borralheiro Pereira / George Nash / Esmeralda Gomes / Nelson Almeida / Carlos Carpetudo

523 Trabalhos de documentação de arte paleolítica realizados no âmbito do projeto PalæoCôa André Tomás Santos / António Fernando Barbosa / Luís Luís / Marcelo Silvestre / Thierry Aubry

537 Imagens fantasmagóricas, silhuetas elusivas: as figuras humanas na arte do Paleolítico Superior da região do Côa Mário Reis

$55^{1}$ Os motivos zoomórficos representados nas placas de tear de Vila Nova de São Pedro (Azambuja, Portugal) Andrea Martins / César Neves / José M. Arnaud / Mariana Diniz

571 Arte Rupestre do Monte de Góios (Lanhelas, Caminha). Síntese dos resultados dos trabalhos efectuados em 2007-2009 Mário Varela Gomes

599 Gravuras rupestres de barquiformes no Monte de S. Romão, Guimarães, Noroeste de Portugal Daniela Cardoso

613 Círculos segmentados gravados na Bacia do Rio Lima (Noroeste de Portugal): contributos para o seu estudo Diogo Marinho / Ana M.S. Bettencourt / Hugo Aluai Sampaio

631 Equídeos gravados no curso inferior do Rio Mouro, Monção (NW Portugal). Análise preliminar Coutinho, L.M. / Bettencourt, A.M.S / Sampaio, Hugo A.S

645 Paletas na Arte Rupestre do Noroeste de Portugal. Inventário preliminar Bruna Sousa Afonso / Ana M. S. Bettencourt / Hugo A. Sampaio 


\section{Pré-História}

661 O projeto Miño/Minho: balanço de quatro anos de trabalhos arqueológicos Sérgio Monteiro-Rodrigues / João Pedro Cunha-Ribeiro / Eduardo Méndez-Quintas / Carlos Ferreira / Pedro Xavier / José Meireles / Alberto Gomes / Manuel Santonja / Alfredo Pérez-González

677 A ocupação paleolítica da margem esquerda do Baixo Minho: a indústria lítica do sítio de Pedreiras 2 (Monção, Portugal) e a sua integração no contexto regional Carlos Ferreira / João Pedro Cunha-Ribeiro / Sérgio Monteiro-Rodrigues / Eduardo Méndez-Quintas / Pedro Xavier / José Meireles / Alberto Gomes / Manuel Santonja / Alfredo Pérez-González

693 O sítio acheulense do Plistocénico médio da Gruta da Aroeira Joan Daura / Montserrat Sanz / Filipa Rodrigues / Pedro Souto / João Zilhão

703 As sociedades neandertais no Barlavento algarvio: modelos preditivos com recurso aos SIG

Daniela Maio

715 A utilização de quartzo durante o Paleolítico Superior no território dos vales dos rios Vouga e Côa

Cristina Gameiro / Thierry Aubry / Bárbara Costa / Sérgio Gomes / Luís Luís / Carmen Manzano / André Tomás Santos

733 Uma perspetiva diacrónica da ocupação do concheiro do Cabeço da Amoreira (Muge, Portugal) a partir da tecnologia lítica Joana Belmiro / João Cascalheira / Célia Gonçalves

745 Novos dados sobre a Pré-história Antiga no concelho de Palmela. A intervenção arqueológica no sítio do Poceirão I

Michelle Teixeira Santos

757 Problemas em torno de Datas Absolutas Pré-Históricas no Norte do Alentejo Jorge de Oliveira

771 Povoamento pré-histórico nas áreas montanhosas do NO de Portugal: o Abrigo 1 de Vale de Cerdeira Pedro Xavier / José Meireles / Carlos Alves

783 Apreciação do povoamento do Neolítico Inicial na Baixa Bacia do Douro. A Lavra I (Serra da Aboboreira) como caso de estudo Maria de Jesus Sanches

797 O Processo de Neolitização na Plataforma do Mondego: os dados do Sector C do Outeiro dos Castelos de Beijós (Carregal do Sal)

João Carlos de Senna-Martinez / José Manuel Quintã Ventura / Andreia Carvalho / Cíntia Maurício

823 Novos trabalhos na Lapa da Bugalheira (Almonda, Torres Novas) Filipa Rodrigues / Pedro Souto / Artur Ferreira / Alexandre Varanda / Luís Gomes / Helena Gomes / João Zilhão

837 A pedra polida e afeiçoada do sítio do Neolítico médio da Moita do Ourives (Benavente, Portugal)

César Neves

857 Casal do Outeiro (Encarnação, Mafra): novos contributos para o conhecimento do povoamento do Neolítico final na Península de Lisboa.

Cátia Delicado / Carlos Maneira e Costa / Marta Miranda / Ana Catarina Sousa

873 Stresse infantil, morbilidade e mortalidade no sítio arqueológico do Neolítico Final/ Calcolítico ( $4^{\circ}$ e $3^{\circ}$ milénio a.C.) do Monte do Carrascal 2 (Ferreira do Alentejo, Beja) Liliana Matias de Carvalho / Sofia N. Wasterlain 
885 Come together: O Conjunto Megalítico das Motas (Monção, Viana do Castelo) e as expressões Campaniformes do Alto Minho Ana Catarina Basílio / Rui Ramos

899 Trabalhos arqueológicos no sítio Calcolítico da Pedreira do Poio Carla Magalhães / João Muralha / Mário Reis / António Batarda Fernandes

913 O sítio arqueológico de Castanheiro do Vento. Da arquitectura do sítio à arquitectura de um território João Muralha Cardoso

925 Estudo zooarqueológico das faunas do Calcolítico final de Vila Nova de São Pedro (Azambuja, Portugal): Campanhas de 2017 e 2018 Cleia Detry / Ana Catarina Francisco / Mariana Diniz / Andrea Martins / César Neves / José Morais Arnaud

943 As faunas depositadas no Museu Arqueológico do Carmo provenientes de Vila Nova de São Pedro (Azambuja): as campanhas de 1937 a 1967 Ana Catarina Francisco / Cleia Detry / César Neves / Andrea Martins / Mariana Diniz / José Morais Arnaud

959 Análise funcional de material lítico em sílex do castro de Vila Nova de S. Pedro (Azambuja, Portugal): uma primeira abordagem Rafael Lima

971 O recinto da Folha do Ouro 1 (Serpa) no contexto dos recintos de fossos calcolíticos alentejanos

António Carlos Valera / Tiago do Pereiro / Pedro Valério / António M. Monge Soares

\section{Proto-História}

987 Produção de sal marinho na Idade do Bronze do noroeste Português. Alguns dados para uma reflexão

Ana M. S. Bettencourt / Sara Luz / Nuno Oliveira / Pedro P. Simões / Maria Isabel C. Alves / Emílio Abad-Vidal

1001 A estátua-menir do Pedrão ou de São Bartolomeu do Mar (Esposende, noroeste de Portugal) no contexto arqueológico da fachada costeira de entre os rios Neiva e Cávado Ana M. S. Bettencourt / Manuel Santos-Estévez / Pedro Pimenta Simões / Luís Gonçalves

1015 O Castro do Muro (Vandoma/Baltar, Paredes) - notas para uma biografia de ocupação da Idade do Bronze à Idade Média

Maria Antónia D. Silva / Ana M. S. Bettencourt / António Manuel S. P. Silva / Natália Félix

1031 Do Bronze Final à Idade Média - continuidades e hiatos na ocupação de Povoados em Oliveira de Azeméis João Tiago Tavares / Adriaan de Man

1041 As faunas do final da Idade do Bronze no Sul de Portugal: leituras desde o Outeiro do Circo (Beja)

Nelson J. Almeida / Íris Dias / Cleia Detry / Eduardo Porfírio / Miguel Serra

1055 A Espada do Monte das Oliveiras (Serpa) - uma arma do Bronze Pleno do Sudoeste Rui M. G. Monge Soares / Pedro Valério / Mariana Nabais / António M. Monge Soares

1065 São Julião da Branca (Albergaria-a-Velha) - Investigação e valorização de um povoado do Bronze Final

António Manuel S. P. Silva / Paulo A. P. Lemos / Sara Almeida e Silva / Edite Martins de Sá

1083 Do castro de S. João ao Mosteiro de Santa Clara: notícia de uma intervenção arqueológica, em Vila do Conde Rui Pinheiro 
1095 O castro de Ovil (Espinho), um quarto de século de investigação - resultados e questões em aberto

Jorge Fernando Salvador / António Manuel S. P. Silva

1111 O Castro de Salreu (Estarreja), um povoado proto-histórico no litoral do Entre Douro e Vouga

Sara Almeida e Silva / António Manuel S. P. Silva / Paulo A. P. Lemos / Edite Martins de Sá

1127 Castro de Nossa Senhora das Necessidades (Sernancelhe): uma primeira análise artefactual Telma Susana O. Ribeiro

${ }_{1141}$ A cividade de Bagunte. O estado atual da investigação Pedro Brochado de Almeida

1153 Zoomorfos na cerâmica da Idade do Ferro no NW Peninsular: inventário, cronologias e significado Nuno Oliveira / Cristina Seoane

1163 Vasos gregos em Portugal: diferentes maneiras de contar a história do intercâmbio cultural na Idade do Ferro

Daniela Ferreira

1175 Os exotica da necrópole da Idade do Ferro do Olival do Senhor dos Mártires (Alcácer do Sal) no seu contexto regional

Francisco B. Gomes

\section{Antiguidade Clássica e Tardia}

1191 O uso de madeira como combustível no sítio da Quinta de Crestelos (Baixo Sabor): da Idade do Ferro à Romanização Filipe Vaz / João Tereso / Sérgio Simões Pereira / José Sastre / Javier Larrazabal Galarza / Susana Cosme / José António Pereira / Israel Espi

1207 Cultivos de Época Romana no Baixo Sabor: continuidade em tempos de mudança? João Pedro Tereso / Sérgio Simões Pereira / Filipe Santos / Luís Seabra / Filipe Vaz

1221 A casa romana na Hispânia: aplicação dos modelos itálicos nas províncias ibéricas Fernanda Magalhães / Diego Machado / Manuela Martins

1235 As pinturas murais romanas da Rua General Sousa Machado, n. ${ }^{5}$ 1, Chaves José Carvalho

1243 Trás do Castelo (Vale de Mir, Pegarinhos, Alijó) - Uma exploração agrícola romana do Douro

Tony Silvino / Pedro Pereira

1255 A sequência de ocupação no quadrante sudeste de Bracara Augusta: as transformações de uma unidade doméstica Lara Fernandes / Manuela Martins

1263 Os Mosaicos com decoração geométrica e geométrico-vegetalista dos sítios arqueológicos da área do Conuentus Bracaraugustanus. Novas abordagens quanto à conservação, restauro, decoração e datação Maria de Fátima Abraços / Licínia Wrench

1277 “Casa Romana” do Castro de São Domingos (Cristelos, Lousada): Escavação, Estudo e Musealização Paulo André de P. Lemos

1291 A arqueobotânica no Castro de Guifões (Matosinhos, Noroeste de Portugal): O primeiro estudo carpológico

Luís Seabra / Andreia Arezes / Catarina Magalhães / José Varela / João Pedro Tereso 
1305 Um Horreum Augustano na Foz do Douro (Monte do Castelo de Gaia, Vila Nova de Gaia) Rui Ramos

1311 Ponderais romanos na Lusitânia: padrões, formas, materiais e contextos de utilização Diego Barrios Rodríguez

1323 Um almofariz centro-itálico na foz do Mondego

Marco Penajoia

1335 Estruturas romanas de Carnide - Lisboa Luísa Batalha / Mário Monteiro / Guilherme Cardoso

1347 O contexto funerário do sector da "necrópole NO" da Rua das Portas de S. Antão (Lisboa): o espaço, os artefactos, os indivíduos e a sua interconectividade na interpretação do passado Sílvia Loja, José Carlos Quaresma, Nelson Cabaço, Marina Lourenço, Sílvia Casimiro, Rodrigo Banha da Silva, Francisca Alves-Cardoso

${ }_{1361}$ Povoamento em época Romana na Amadora - resultados de um projeto pluridisciplinar Gisela Encarnação / Vanessa Dias

1371 A Arquitectura Residencial em Mirobriga (Santiago do Cacém): contributo a partir de um estudo de caso Filipe Sousa / Catarina Felício

${ }_{1385}$ O fim do ciclo. Saneamento e gestão de resíduos nos edifícios termais de Mirobriga (Santiago do Cacém)

Catarina Felício / Filipe Sousa

1399 Balsa, Topografia e Urbanismo de uma Cidade Portuária Vítor Silva Dias / João Pedro Bernardes / Celso Candeias / Cristina Tété Garcia

1413 No Largo das Mouras Velhas em Faro (2017): novas evidências da necrópole norte de Ossonoba e da sua ocupação medieval Ricardo Costeira da Silva / Paulo Botelho / Fernando Santos / Liliana Nunes

1429 Instrumentos de pesca recuperados numa fábrica de salga em Ossonoba (Faro) Inês Rasteiro / Ricardo Costeira da Silva / Paulo Botelho

1439 A Necrópole Romana do Eirô, Duas Igrejas (Penafiel): intervenção arqueológica de 2016 Laura Sousa / Teresa Soeiro

1457 Ritual, descarte ou afetividade? A presença de Canis lupus familiaris na Necrópole Noroeste de Olisipo (Lisboa)

Beatriz Calapez Santos / Sofia Simões Pereira / Rodrigo Banha da Silva / Sílvia Casimiro / Cleia Detry / Francisca Alves Cardoso

1467 Dinâmicas económicas em Bracara na Antiguidade Tardia Diego Machado / Manuela Martins / Fernanda Magalhães / Natália Botica

1479 Cerâmicas e Vidros da Antiguidade Tardia do Edifício sob a Igreja do Bom Jesus (Vila Nova de Gaia) Joaquim Filipe Ramos

1493 Novos contributos para a topografia histórica de Mértola no período romano e na Antiguidade Tardia Virgílio Lopes

\section{8. Época Medieval}

1511 Cerâmicas islâmicas no Garb setentrional "português": algumas evidências e incógnitas Constança dos Santos / Helena Catarino / Susana Gómez / Maria José Gonçalves / Isabel Inácio / Gonçalo Lopes / Jacinta Bugalhão / Sandra Cavaco / Jaquelina Covaneiro / Isabel Cristina Fernandes / Ana Sofia Gomes 
1525 Contributo para o conhecimento da cosmética islâmica, em Silves, durante a Idade Média Rosa Varela Gomes

1537 Yábura e o seu território - uma análise histórico-arqueológica de Évora entre os séculos VIII-XII José Rui Santos

1547 A encosta sul do Castelo de Palmela - resultados preliminares da escavação arqueológica Luís Filipe Pereira / Michelle Teixeira Santos

1559 A igreja de São Lourenço (Mouraria, Lisboa): um conjunto de silos e de cerâmica medieval islâmica

Andreia Filipa Moreira Rodrigues

1571 O registo material de movimentações populacionais no Médio Tejo, durante os séculos XII-XIII. Dois casos de "sunken featured buildings", nos concelhos de Cartaxo e Torres Novas Marco Liberato / Helena Santos / Nuno Santos

1585 O nordeste transmontano nos alvores da Idade média. Notas para reflexão Ana Maria da Costa Oliveira

1601 Sepulturas escavadas na rocha do Norte de Portugal e do Vale do Douro: primeiros resultados do Projecto SER-NPVD

Mário Jorge Barroca / César Guedes / Andreia Arezes / Ana Maria Oliveira

1619 "Portucalem Castrum Novum" entre o Mediterrâneo e o Atlântico: o estudo dos materiais cerâmicos alto-medievais do arqueossítio da rua de D. Hugo, nํ. 5 (Porto) João Luís Veloso

1627 A Alta Idade Média na fronteira de Lafões: notas preliminares sobre a Arqueologia no Concelho de Vouzela

Manuel Luís Real / Catarina Tente

1641 Um conjunto cerâmico medieval fora de portas: um breve testemunho aveirense Susana Temudo

${ }_{1651}$ Os Lóios do Porto: uma perspetiva integrada no panorama funerário da Baixa Idade Média à Época Moderna em meios urbanos em Portugal

Ana Lema Seabra

1659 O Caminho Português Interior de Santiago como eixo viário na Idade Média Pedro Azevedo

1665 Morfologia Urbana: Um exercício em torno do Castelo de Ourém André Donas-Botto / Jaqueline Pereira

1677 Intervenção arqueológica na Rua Marquês de Pombal/Largo do Espírito Santo (Bucelas, Loures)

Florbela Estêvão / Nathalie Antunes-Ferreira / Dário Ramos Neves / Inês Lisboa

1691 O Cemitério Medieval do Poço do Borratém e a espacialidade funerária na cidade de Lisboa Inês Belém / Vanessa Filipe / Vasco Noronha Vieira / Sónia Ferro / Rodrigo Banha da Silva

1705 Um Espaço Funerário Conventual do séc. XV em Lisboa: o caso do Convento de São Domingos da Cidade Sérgio Pedroso / Sílvia Casimiro / Rodrigo Banha da Silva / Francisca Alves Cardoso

\section{9. Época Moderna e Contemporânea}

1721 Arqueologia Moderna em Portugal: algumas reflexões críticas em torno da quantificação de conjuntos cerâmicos e suas inferências históricas e antropológicas Rodrigo Banha da Silva / André Bargão / Sara da Cruz Ferreira

1733 Faianças de dois contextos entre os finais do século XVI e XVIII do Palácio dos Condes de Penafiel, Lisboa

Martim Lopes / Tomás Mesquita 
1747 Um perfil de consumo do século XVIII na foz do Tejo: O caso do Mercado da Ribeira, Lisboa Sara da Cruz Ferreira / Rodrigo Banha da Silva / André Bargão

1761 Os Cachimbos dos Séculos XVII e XVIII do Palácio Mesquitela e Convento dos Inglesinhos (Lisboa)

Inês Simão / Marina Pinto / João Pimenta / Sara da Cruz Ferreira / André Bargão / Rodrigo Banha da Silva

1775 "Tomar os fumos da erua que chamão em Portugal erua sancta». Estudo de Cachimbos provenientes da Rua do Terreiro do Trigo, Lisboa

Miguel Martins de Sousa / José Pedro Henriques / Vanessa Galiza Filipe

1787 Cachimbos de Barro Caulínitico da Sé da Cidade Velha (República de Cabo Verde)

Rodrigo Banha da Silva / João Pimenta / Clementino Amaro

1801 Algumas considerações sobre espólio não cerâmico recuperado no Largo de Jesus (Lisboa) Carlos Boavida

1815 Adereços de vidro, dos séculos XVI-XVIII, procedentes do antigo Convento de Santana de Lisboa (anéis, braceletes e contas)

Joana Gonçalves / Rosa Varela Gomes / Mário Varela Gomes

1837 Da ostentação, luxo e poder à simplicidade do uso quotidiano: arqueologia e simbologia de joias e adornos da Idade Moderna Portuguesa Jéssica Iglésias

1849 Os amuletos em Portugal - dos objetos às superstições: o coral vermelho Alexandra Vieira

1865 Cerâmicas de Vila Franca de Xira nos séculos XV e XVI Eva Pires

1879 «Não passa por teu o que me pertence». Marcas de individualização associadas a faianças do Convento de Nossa Senhora de Aracoeli, Alcácer do Sal Catarina Parreira / Íris Fragoso / Miguel Martins de Sousa

1891 Cerâmica de Leiria: alguns focos de produção

Jaqueline Pereira / André Donas-Botto

1901 Os Fornos na Rua da Biquinha, em Óbidos Hugo Silva / Filipe Oliveira

1909 A casa de Pêro Fernandes, contador dos contos de D. Manuel I: o sítio arqueológico da Silha do Alferes, Seixal (século XVI) Mariana Nunes Ferreira

1921 O Alto da Vigia (Sintra) e a vigilância e defesa da costa Alexandre Gonçalves / Sandra Santos

1937 O contexto da torre sineira da Igreja de Santa Maria de Loures Paulo Calaveira / Martim Lopes

1949 A Necrópole do Hospital Militar do Castelo de São Jorge e as práticas funerárias na Lisboa de Época Moderna Susana Henriques / Liliana Matias de Carvalho / Ana Amarante / Sofia N. Wasterlain

1963 SAND - Sarilhos Grandes Entre dois Mundos: o adro da Igreja e a Paleobiologia dos ossos humanos recuperados

Paula Alves Pereira / Roger Lee Jesus / Bruno M. Magalhães

1975 Expansão urbana da vila de Cascais no século XVII e XVIII: a intervenção arqueológica na Rua da Vitória no 15 a 17

Tiago Pereira / Vanessa Filipe

1987 Novos dados para o conhecimento do Urbanismo de Faro em época Moderna Ana Rosa 
1995 Um exemplo de Arqueologia Urbana em Alcoutim: o Antigo Edifício dos CTT Marco Fernandes / Marta Dias / Alexandra Gradim / Virgílio Lopes / Susana Gómez Martínez

2007 Palácio dos Ferrazes (Rua das Flores/Rua da Vitória, Porto): a cocheira de Domingos Oliveira Maia

Francisco Raimundo

2021 As muitas vidas de um edifício urbano: História, Arqueologia e Antropologia no antigo Recreatório Paroquial de Penafiel Helena Bernardo / Jorge Sampaio / Marta Borges

2035 O convento de Nossa Senhora da Esperança de Ponta Delgada: o contributo da arqueologia para o conhecimento de um monumento identitário João Gonçalves Araújo / N’Zinga Oliveira

2047 Arqueologia na ilha do Corvo... em busca da capela de Nossa Senhora do Rosário Tânia Manuel Casimiro / José Luís Neto / Luís Borges / Pedro Parreira

2059 Perdidos à vista da Costa. Trabalhos arqueológicos subaquáticos na Barra do Tejo Jorge Freire / José Bettencourt / Augusto Salgado

2071 Arqueologia marítima em Cabo Verde: enquadramento e primeiros resultados do projecto CONCHA

José Bettencourt / Adilson Dias / Carlos Lima / Christelle Chouzenoux / Cristóvão Fonseca / Dúnia Pereira / Gonçalo Lopes / Inês Coelho / Jaylson Monteiro / José Lima / Maria Eugénia Alves / Patrícia Carvalho / Tiago Silva

2085 Trabalhos arqueológicos na Cidade Velha (Ribeira Grande de Santiago, Cabo Verde): reflexões sobre um projecto de investigação e divulgação patrimonial André Teixeira / Jaylson Monteiro / Mariana Mateus / Nireide Tavares / Cristovão Fonseca / Gonçalo C. Lopes / Joana Bento Torres / Dúnia Pereira / André Bargão / Aurélie Mayer / Bruno Zélie / Carlos Lima / Christelle Chouzenoux / Inês Henriques / Inês Pinto Coelho / José Lima / Patrícia Carvalho / Tiago Silva

2103 A antiga fortificação de Quelba / Khor Kalba (E.A.U.). Resultados de quatro campanhas de escavações, problemáticas e perspectivas futuras Rui Carita / Rosa Varela Gomes / Mário Varela Gomes / Kamyar Kamyad

2123 Colónias para homens novos: arqueologia da colonização agrária fascista no noroeste ibérico Xurxo Ayán Vila / José Mạ . Señorán Martín 


\title{
ARQUEOLOGIA PÚBLICA E O CASO DA LOCALIDADE DA MATA (TORRES NOVAS)
}

\author{
Cláudia Manso ${ }^{1}$, Ana Rita Ferreira ${ }^{2}$, Cristiana Ferreira ${ }^{3}$, Vanessa Cardoso Antunes ${ }^{4}$
}

\begin{abstract}
RESUMO
Discutem-se formulações de 'valor', 'identidade' e 'lugar', partindo de M. Díaz-Andreu (2017: 2-6) e de P. G. Gould (2016:1-18), bem como os termos em que se estrutura uma abordagem participativa e crítica da comunidade na gestão cultural local com base na seleção comparativa de convenções internacionais do património. Palavras-chave: Valor patrimonial, Micro gestão pela comunidade.
\end{abstract}

\begin{abstract}
Formulations of 'value', 'identity' and 'place' are discussed, according to M. Díaz-Andreu (2017: 2-6) and P. G. Gould (2016:1-18), as well as the terms in which a participatory and critical approach by the community on local cultural management is structured, grounded on the comparative selection of international heritage conventions. Keywords: Heritage value, Micromanagement by the community.
\end{abstract}

A formulação do conceito de valor numa perspetiva top-down é doutrinalmente patente no normativo internacional das primeiras concertações acerca do património cultural. A Carta de Atenas (1931), enquanto referência no estabelecimento de diretrizes para o património existente em contexto urbano, estipula uma noção estanque de monumento e da envolvente, assentes na intervenção mínima sobre essas materialidades, uma perspetiva do ato de conservação que é, tecnicamente, garantia de antiguidade e de autenticidade. Alternativamente, a Carta de Veneza (1964) assume o caráter permanente das alterações resultantes de operações realizadas na conservação do monumento, processo que implica a integração da componente histórica associada, mas sobretudo centrado na manutenção por reutilização do elemento edificado. Ambas as convenções partilham, todavia, a ideia de uma transmissão da mensagem do Passado através de um filtro disciplinar e da racionalização do valor patrimonial. Se, por um lado, a indispensabilidade do bem provém da significação coletiva, reiteradamente associada ao pendor civilizacional dessa legibilidade cultural, por outro, formaliza-se uma necessidade coetânea de quantificar a respetiva valoração através dos ditames das ciências aplicadas ao património. A dinâmica específica de salvaguarda do património influencia diretamente o valor social e, em última instância, condiciona a tipologia e o número de testemunhos a preservar.

A invariabilidade do conceito de valor é ainda o esteio da Convenção do Património Mundial (1972), e das subsequentes Orientações Técnicas para a integração do património cultural e/ou natural ${ }^{5}$, qualificado pelo seu Valor Universal Excecional, em Listas do Património Mundial. Esta imutabilidade conceptual de valor assegura a argumentação objetiva e científica que está na base da tomada de decisões pelo Comité do Património Mundial no decurso do processo de avaliação dos bens indicados como passíveis

\footnotetext{
1. Direção-geral do Património Cultural; claudiamanso@dgpc.pt

2. Centro Português de Geo-história e Pré-história; aaritaferreira@gmail.com

3. Centro de Geociências (Universidade de Coimbra, ulD73-FCT) e Centro Português de Geo-história e Pré-história; ferreira.cris.oo@gmail.com
}

4. Centro Português de Geo-história e Pré-história; vanessanx@yahoo.com.br

5. As definições de património cultural e de património natural são descritas no conteúdo dos artigos 1.. e 2.. da Convenção para a Proteção do Património Mundial, Cultural e Natural (Paris, 1972). 
de inscrição nessas listas. A pirâmide decisória, encimada pelo Comité, define então o Valor Universal Excecional do bem, entendido na sua inestimável singularidade cultural e/ou natural, transfronteiriça e transgeracional, por serem cumpridos critérios de avaliação preestabelecidos ${ }^{6}$, por se verificar a existência de um sistema específico de proteção e gestão e, também, por se estabelecerem as condições de autenticidade e/ou de integridade.

Entre os documentos normativos exarados pelo Conselho da Europa, a Convenção de Granada (1985) foi além do âmbito de acordos anteriores, ao considerar a importância do uso contemporâneo dos monumentos a par do respetivo valor histórico e artístico, balanço que seria alargado pela Convenção de Malta (1992) cujo texto reconhece o valor dos costumes e/ou tradições na compreensão e investigação científica do Passado humano. Em sede de arqueologia pública, essa visão integral da paisagem arqueológica assenta na consideração de que valores sociais, culturais e estéticos conjugados vêm conformar as relações entre os residentes e intensificar a perceção simbólica do lugar como herança cultural comum (Richardson \& Almansa-Sánchez, 2015).

A inversão da formulação do conceito de valor através de uma abordagem bottom-up, agora alicerçada na participação ativa do público e das entidades locais e regionais no processo decisório, deriva das circunstâncias normativas proporcionadas pela Carta de Lausanne (1990) e pela Convenção de Florença (2000) no que concernem as questões ambientais e do património arqueológico. E, no mesmo sentido, a Carta de Cracóvia (200o) equipara o contributo de indivíduos e instituições na conservação do património construído, valorizando os monumentos enquanto traduções individuais da memória coletiva e assumindo o peso que uma gestão descentralizada tem no desenvolvimento sustentável, económico e social das comunidades.

A Convenção de Faro (2005) alargaria o alcance desses princípios ao estabelecer taxativamente que o envolvimento prático na vida cultural é um direito fundamental que complementa o próprio exercício

6. As versões de 1977, 1980, 1983, 1984, 1988, 1992, 1994, 1996, 1997/1999, 2005 e 2008 das Orientações Técnicas para a Aplicação da Convenção do Património Mundial apresentam, ainda que reformulados, seis critérios supletivos de definição do Valor Universal Excecional do património cultural. da liberdade cultural. E arroja a definição de comunidade patrimonial como o conjunto de pessoas que, por vontade individual, seleciona quais os aspetos a valorizar no próprio património cultural. O teor inerente é simultaneamente conciliador das eventuais contradições valorativas que surgem em contextos de grande diversidade cultural como os que advieram da migração massiva historicamente coincidente com as transformações sociopolíticas e geoestratégicas do último decénio.

Em Portugal, raros serão os exemplos de comunidades que espontaneamente atribuem um valor social inequívoco ao património arqueológico e, ainda mais raros os casos em que esse ativismo se traduz, a nível local, na salvaguarda patrimonial através de um claro compromisso político-financeiro. O paradigma comum será talvez o que resulta de uma perceção mormente centralizadora da gestão patrimonial e, ainda que vigorando um quadro legislativo promotor do entrosamento entre público e património, existem mecanismos de bloqueio à participação do cidadão comum na atividade arqueológica quando efetuada sem a orientação de pessoal formado em arqueologia.

Uma significativa percentagem dos investigadores e dos técnicos públicos e privados do património condescende à suspeição de que as iniciativas encetadas por leigos em matérias da arqueologia redundam na produção de discursos cientificamente duvidosos. Tal tendência tem uma relação direta com a ética académica e a ética profissional dos cientistas humanos, e explica-se sobretudo pela marcada distinção que existe entre a arqueologia e os costumes (Van Den Vries, 2014). Esta disposição não cooperante entre a arqueologia e as tradições prolongar-se-á em países herdeiros de uma ética eurocêntrica, reconduzível à Carta de Veneza, descurando-se o significado do sítio - i.e. o valor que, sendo inerente ao lugar, supera o sentido utilitário do espaço -, e silenciando-se perspetivas do património conduzidas por vozes amadoras locais (Díaz-Andreu, 2016).

Veja-se o caso da localidade da Mata, onde, no âmbito do acompanhamento arqueológico da Empreitada Águas do Ribatejo Subsistemas Torres Novas - Chancelaria / Pedrogão, foram registadas 45 estruturas negativas maioritariamente de cariz antrópico, patentes no substrato geológico, cuja morfologia, contexto estratigráfico e materiais associados, compeliriam preliminarmente à pluralização de hipóteses funcionais e de atribuições cronológicas na 
avaliação do conjunto que seria intervencionado. À plausibilidade desses dados arqueológicos ambivalentes, seguiu-se a conservação pelo registo, com posterior destruição dos achados.

No concelho de Torres Novas, o caso da comunidade da Mata poderá constituir um baluarte da defesa do património arqueológico a partir de uma perspetiva de tipo identitário. Porém, tal afirmação depende da motivação subjacente ao movimento de contestação dos residentes e dos termos em que se valorou aquele património e se alicerçou a defesa dos vestígios por serem dos seus antepassados. Por conseguinte, importa avaliar se a população da Mata congregará um ou ambos os tipos de comunidade que se apresentam como hipóteses (Marshall, 2002):

a) Um conjunto de residentes cujo ativismo resulta da valorização dos recursos específicos do lugar natal, reforçados pela descoberta de vestígios arqueológicos cuja antiguidade e autenticidade foram metodologicamente atestadas;

b) Um conjunto de residentes que conota emocionalmente as descobertas arqueológicas enquanto ligação à progénie e tenciona transmitir, aos seus descendentes, factos e/ou bens concernentes a um antepassado comum, porque circunscritos ao lugar da génese comunitária.

Para tal realizar-se-á uma pesquisa de opinião, por ora metodologicamente apresentada em fase bastante prematura (Gould, 2016). Este inquérito autoadministrado permitirá a obtenção de dados necessários ao ensaio de cariz sociométrico sobre o qual assentará um modelo de sustentabilidade orientado para projetos de pequena dimensão com o benefício da presença de atividade arqueológica (vide infra).

\begin{tabular}{|l|l|l|l|}
\hline \multicolumn{4}{|l|}{ 1. Avalio a importância dos achados arqueológicos para a história da aldeia: } \\
\hline Sem importância & Pouco importantes & Muito importantes & Essenciais \\
\hline
\end{tabular}

\begin{tabular}{|l|l|l|l|}
\hline 2. Avalio a relevância dos achados arqueológicos na história da minha família: \\
\hline Sem relevância & Pouco relevantes & Muito relevantes & Fundamentais \\
\hline
\end{tabular}

\begin{tabular}{|l|l|l|l|}
\hline 3. O valor dos achados arqueológicos resulta de serem: \\
\hline Raros/Antigos & $\begin{array}{l}\text { Conhecidos pelas pessoas } \\
\text { da aldeia }\end{array}$ & $\begin{array}{l}\text { Importantes para } \\
\text { os arqueólogos }\end{array}$ & Uma atração turística \\
\hline
\end{tabular}

\begin{tabular}{|l|l|l|l|}
\hline \multicolumn{2}{|l|}{ 4. Identifico-me como 'matense' porque: } \\
\hline Nasci na aldeia & $\begin{array}{l}\text { Conheço as tradições } \\
\text { e costumes }\end{array}$ & $\begin{array}{l}\text { A minha família mora } \\
\text { na aldeia }\end{array}$ & Valorizo o património \\
\hline
\end{tabular}

\begin{tabular}{|l|l|l|l|}
\hline 5. Os achados arqueológicos interessam-me porque: \\
\hline É património da aldeia & $\begin{array}{l}\text { Arqueólogos os consideram } \\
\text { únicos }\end{array}$ & São raros no concelho & Não me interessam \\
\hline
\end{tabular}

\begin{tabular}{|l|l|l|l|}
\hline 6. Os achados arqueológicos são antigos porque: \\
\hline São romanos & $\begin{array}{l}\text { Já eram conhecidos pelos } \\
\text { meus avós }\end{array}$ & $\begin{array}{l}\text { Contam a história } \\
\text { da aldeia }\end{array}$ & $\begin{array}{l}\text { Foram escavados } \\
\text { por arqueólogos }\end{array}$ \\
\hline
\end{tabular}

\begin{tabular}{|l|l|l|l|}
\hline 7. Defendo os costumes/tradições da minha aldeia porque: \\
\hline $\begin{array}{l}\text { Celebro as festas locais em } \\
\text { família }\end{array}$ & Defendo qualquer património & $\begin{array}{l}\text { Perpetuam a memória } \\
\text { dos avós }\end{array}$ & Não defendo \\
\hline
\end{tabular}

\begin{tabular}{|l|l|l|l|}
\hline 8. O património arqueológico conduz a benefícios económicos à aldeia porque: \\
\hline Atrai visitantes & Dinamiza o comércio & Cria emprego & Não traz benefícios \\
\hline
\end{tabular}

\begin{tabular}{|l|l|l|l|}
\hline \multicolumn{2}{|l|}{ 9. As descobertas arqueológicas mudaram a minha perspetiva do património porque: } \\
\hline É uma atividade científica & $\begin{array}{l}\text { A aldeia é mais antiga } \\
\text { do que pensava }\end{array}$ & $\begin{array}{l}\text { Observei vestígios } \\
\text { de perto }\end{array}$ & $\begin{array}{l}\text { Atrasam a conclusão } \\
\text { das obras }\end{array}$ \\
\hline
\end{tabular}




\section{BIBLIOGRAFIA}

(1990) - Carta sobre a Proteção e a Gestão do Património Arqueológico. Carta de Lausanne, Comité Internacional para a Gestão do Património Arqueológico.

(1931) - Conferência Internacional de Atenas sobre o Restauro dos Monumentos - Carta de Atenas. Atenas, 21 a 30 de outubro de 1931 .

(200o) - Conferência Internacional sobre Conservação. Carta de Cracóvia, Princípios para a Conservação e o Restauro do Património Construído. Cracóvia, 26 de outubro de 2000.

(1972) - Conferência Geral da Organização das Nações Unidas para a Educação, Ciência e Cultura - Recomendação de Paris, Convenção para a Proteção do Património Mundial, Cultural e Natural. Paris, 17 de outubro a 23 de novembro de 1972.

(200o) - Convenção Europeia da Paisagem - Convenção de Florença, Conselho da Europa. Florença, 20 de outubro de 2000 .

(1992) - Convenção Europeia para a Proteção do Património Arqueológico - Convenção de Malta, Conselho da Europa. La Valetta, 16 de janeiro de 1992.

(1985) - Convenção para a Salvaguarda do Património Arquitetónico da Europa, Convenção de Granada, Conselho da Europa. Granada, 3 de outubro de 1985.

(2005) - Convenção Quadro do Conselho da Europa Relativa ao Valor do Património Cultural para a Sociedade, Convenção de Faro. Faro, 27 de outubro de 2005.

(1964) - II Congresso Internacional de Arquitetos e Técnicos de Monumentos Histórico, Carta de Veneza, Carta Internacional sobre a Conservação e Restauro dos Monumentos e Sítios. Veneza, 25 a 31 de maio de 1964.

(2010) - Orientação para a elaboração de Declarações de Valor Universal Excecional para bens do Património Mundial - Centro do Património Mundial da UNESCO. Organização das Nações Unidas para a Educação, Ciência e Cultura. Julho de 2010, Anexo 3: Alterações aos critérios do Património Mundial em diferentes versões das Orientações Técnicas (OG), pp.19-22.

(2013) - Orientações Técnicas para Aplicação da Convenção do Património Mundial do Comité Intergovernamental para a Proteção do Património Mundial, Cultural e Natural. Organização das Nações Unidas para a Educação, Ciência e Cultura. Julho de 2013, Cap. II., Número do Parágrafo. 45-88.

DÍAZ-ANDREU, Margarita (2016) - Heritage Values and the Public. Journal of Community Archaeology \& Heritage. 4:1, pp. 2-6.

GOULD, Peter G. (2016) - On the Case: Method in Public and Community Archaeology. Public Archaeology. 15:1, pp. 5-22.
GRIMA, Reuben (2016) But Isn't All Archaeology 'Public' Archaeology? Public Archaeology. August issue, pp. 1-16.

HOLTORF, Cornelius (2007) - Can you hear me at the back? Archaeology, communication and society. European Journal of Archaeology. 10: 2-3, pp. 149-165.

MARSHALL, Yvonne (2002) - What is community archaeology? World Archaeology . 34:2, pp. 211-219.

MASCARENHAS, José Manuel; SOARES, Joaquina; SILVA, Carlos Tavares da (1986) - O Património Histórico-Cultural e os Estudos de Impacte Ambiental: proposta de metodologia para a avaliação do impacte das barragens. Trabalhos de Arqueologia do Sul. 1, pp. 7-16.

MATSUDA, Akira (2004) - The Concept of 'the Public' and the Aims of Public Archaeology. Institute of Archaeology. 15, pp. 66-76-

MOSHENSKA, Gabriel (2017) - Key Concepts in Public Archaeology. Londres: UCL Press, 238 p.

MOSHENSKA, Gabriel; DHANJAL, Sarah (2011) - Community Archaeology: Themes, Methods and Practices. Oxford: Oxbow Books, $135 \mathrm{p}$.

OKAMURA, Katsuyuki; MATSUDA, Akira (2011) - New Perspectives in Global Public Archaeology. Nova Iorque: Springer, $275 \mathrm{p}$.

OLDHAM, Mark (2018) - Bridging the Gap: Classification, Theory and Practice in Public Archaeology. Public Archaeology. August issue, pp. 1-16.

PEREIRA, João Paulo; MARTINS, Ivone Pereira (1995) Estudos de Impacte Ambiental: a vertente arqueológica. Almadan. Almada. Série II. 4, pp. 87-93.

RICHARDSON, Lorna-Jane; ALMANSA-SÁNCHEZ, Jaime (2015) - Do you even know what public archaeology is? Trends, theory, practice, ethics. World Archaeology. 47:2, pp. 195-211.

SCHADLA-HALL, Tim R. (1999) - Editorial: Public Archaeology. European Journal of Archaeology. 2:2, pp. 147-58.

SIMPSON, Faye (2008) - Community Archaeology Under Scrutiny. Conservation and Management of Archaeological Sites. 10:1, pp. 3-16.

TULLY, Gemma (2007) - Community archaeology: general methods and standards of practice. Public Archaeology. 6:3, pp. 155-187.

VAN DEN DRIES, Monique H. (2014) - Community Archaeology in the Netherlands. 'Journal Of Community Archaeology and Heritage'. 1:1, pp. 69-88. 



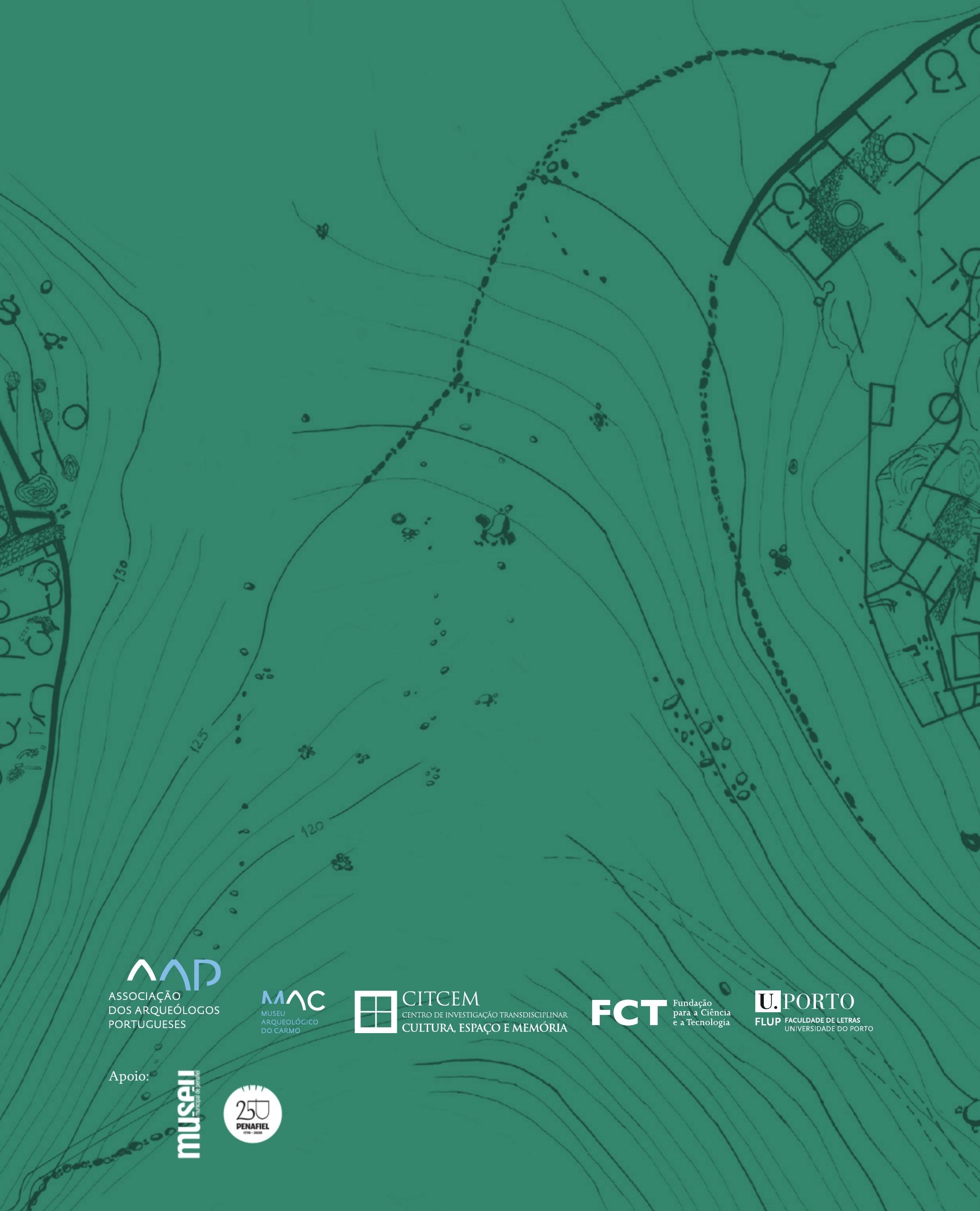

